\title{
Rendimento e Características Físicas dos Óleos de Nim (Azadirachta indica) e Mamona (Ricinus communis)
}

\author{
Juarez Benigno Paes ${ }^{1}$, Ademilson Daniel de Souza ${ }^{2}$, Carlos Roberto de Lima², \\ Gregório Mateus Santana ${ }^{3}$
}

${ }^{1}$ Departamento de Ciências Florestais e da Madeira, Universidade Federal do Espírito Santo - UFES, Jerônimo Monteiro/ES, Brasil

${ }^{2}$ Unidade Acadêmica de Engenharia Florestal, Universidade Federal de Campina Grande - UFCG, Patos/PB, Brasil ${ }^{3}$ Programa de Pós-graduação em Ciências Ambientais e Florestais, Universidade Federal Rural do Rio de Janeiro - UFRRJ, Seropédica/RJ, Brasil

\begin{abstract}
RESUMO
A pesquisa objetivou avaliar o rendimento e a viscosidade de óleos de nim (Azadirachta indica) e mamona (Ricinus communis). Os frutos de nim foram coletados no Núcleo de Pesquisa do Semiárido, em Patos, Paraíba, e os de mamona, às margens do Rio Espinharas, Patos e em Igaracy, Paraíba. Os frutos foram beneficiados no Laboratório de Tecnologia de Produtos Florestais, em Patos. Foram retiradas amostras de sementes para a determinação do teor de umidade e do rendimento em óleos. Os óleos foram extraídos com álcool etílico absoluto e empregados no preparo de soluções com os óleos de nim e mamona. Determinaram-se a densidade e a viscosidade das soluções. A mamona teve menor teor de umidade e rendimento em óleo que o nim. A densidade e a viscosidade do óleo de nim foram menores que o da mamona. Uma maior quantidade de óleos de mamona proporcionou aumento na densidade e na viscosidade das soluções preparadas.
\end{abstract}

Palavras-chave: extração de óleos, preparo de soluções de óleos, densidade, viscosidade.

\section{Yield and Physical Characteristics of Neem (Azadirachta indica) and Castor (Ricinus communis) Oils}

\begin{abstract}
This work aimed to evaluate the yield and viscosity of neem (Azadirachta indica) and castor (Ricinus communis) oils. Neem fruits were collected at the 'Núcleo de Pesquisa do Semi-Árido, municipality of Patos, Paraíba state, and castor plants were collected along the Espinharas River margins, municipalities of Patos and Igaracy, Paraíba state, Brazil. The fruits were beneficiated at the Forest Products Technology Laboratory in Patos. Seed samples were used for determination of moisture content and yield of oils from the studied species. The oils were extracted with absolute ethyl alcohol and employed in the preparation of neem and castor oil solutions. The density and viscosity of solutions were determined. Castor oil presented lower moisture content and yield compared with neem oil. The density and viscosity of neem oil were lower than those of castor oil. A larger amount of castor oil provided an increase in the density and viscosity of the prepared solutions.
\end{abstract}

Keywords: extraction of oils, preparation of oil solutions, density, viscosity. 


\section{INTRODUÇÃO}

O nim (Azadirachta indica A. Juss) é uma planta que pertence à família Meliaceae, de origem asiática, muito resistente e de rápido crescimento, alcançando normalmente de 10 a $15 \mathrm{~m}$ de altura; produz madeira avermelhada, dura e resistente ao ataque de cupins e ao apodrecimento (Araújo et al., 2000; Martinez, 2002).

Os frutos, sementes, óleo, folhas, cascas do caule e raízes do nim possuem os mais variados usos antissépticos e antimicrobianos. O óleo e seus isolados inibem o desenvolvimento de fungos em homens e animais. O óleo é composto basicamente de triglicerídeos de oleico, esteárico, linoleico e palmítico, sendo usado principalmente em lamparinas, sabões e outros produtos não comestíveis (Mossini \& Kemmelmeier, 2005; Carvalho et al., 2008). Porém, após 20 dias em contato com o solo, o óleo se deteriora (Soglia et al., 2006), dificultando seu emprego para o tratamento de madeira, uma vez que os princípios ativos das substâncias empregadas para esta finalidade devem persistir por longo tempo nas peças tratadas.

A mamona (Ricinus communis $\mathrm{L}$ ) é uma planta oleaginosa, pertencente à família Euforbiaceae, originária da África e que chegou ao Brasil no Período Colonial (Ventura, 1990). Em função de suas características de robustez e adaptabilidade, tem sido estudada e explorada, para atender aos programas de produção de biocombustível e para fixar o homem no campo, principalmente no semiárido brasileiro (Machado et al., 1998).

A planta, em virtude da alta capacidade de produção de óleos por área e das perspectivas de melhoria da produtividade; do baixo custo de produção; da alta adaptabilidade climática; da baixa exigência de solos, e da não competitividade com os óleos comestíveis, é uma excelente alternativa como combustível e lubrificante (Companhia Energética de Minas Gerais - CEMIG, 1986).

No Nordeste brasileiro, existem mais de 90 variedades de mamona, que iniciam a produção no primeiro ano de vida (Machado et al., 1998). Em função do grande número de variedades, os teores de óleo podem variar de 44 a 55\% da massa seca das sementes.

Para determinados fins, o óleo de mamona é quase insubstituível. É indicado para lubrificação de engrenagens sujeitas ao esfriamento e à ação da água, por aderir bem às superfícies molhadas, ao contrário dos demais óleos (Machado et al., 1998).

Algumas pesquisas realizadas por Paes et al. (2010, 2011, 2012), com o intuito de avaliar a eficiência dos óleos de nim e de mamona na melhoria da resistência da madeira de sumaúma (Ceiba pentandra) a cupins xilófagos e a fungos deterioradores naturalmente existentes no solo, revelaram que os óleos de nim e de mamona, nas retenções de 10 a $16 \mathrm{~kg}$ de solução. $\mathrm{m}^{-3}$ de madeira, foram pouco eficazes na proteção da madeira. Como a resistência da madeira tratada está relacionada com a retenção dos princípios ativos dos produtos empregados, espera-se que retenções mais elevadas, na ordem de 50 a $60 \mathrm{~kg}$ de solução. $\mathrm{m}^{-3} \mathrm{de}$ madeira, possam proporcionar melhores resultados que os obtidos pelos autores citados.

A viscosidade da solução de tratamento está relacionada com a sua facilidade de penetração na parede celular, em que soluções menos viscosas não necessitariam de ser diluídas ou aquecidas para penetrarem e se difundirem na madeira (Paes, 1997), proporcionando uma maior fixação e retenção. Dessa forma, também se geraria economia com o emprego de reagentes para a diluição dos produtos químicos, principalmente oleosos, ou o uso de energia para o aquecimento da solução, com o intuito de reduzir sua viscosidade.

Esta pesquisa teve como objetivo avaliar o rendimento, as características físicas e a viscosidade de óleos de sementes de nim e mamona em plantas cultivadas no semiárido brasileiro, além de preparar soluções com os óleos com o intuito de caracterizá-las para o tratamento de madeiras.

\section{MATERIAL E MÉTODOS}

\subsection{Colheita, beneficiamento e secagem dos frutos de nim e de mamona}

Os frutos de nim (Azadirachta indica A. Juss) foram coletados em um plantio experimental existente no Núcleo de Pesquisa do Semiárido (NUPEARIDO), pertencente à Universidade Federal de Campina Grande (UFCG), localizado no município de Patos-PB. Já os frutos de mamona (Ricinus communis $\mathrm{L}$ ) foram coletados de várias plantas que crescem às margens 
do Rio Espinharas, em Patos-PB e no município de Igaracy-PB.

Depois de coletados, os frutos de nim foram armazenados em geladeira e, quando a quantidade colhida foi suficiente para a extração dos óleos, foram despolpados sob água corrente, ao serem escarificados manualmente com uma peneira de malha de $2 \times 3 \mathrm{~mm}$. Foram secos à sombra no Laboratório de Tecnologia de Produtos Florestais (LTPF) da Unidade Acadêmica de Engenharia Florestal (UAEF) do Centro de Saúde e Tecnologia Rural (CSTR) da UFCG. Depois de secos, o tegumento foi removido manualmente e os cotilédones, armazenados em sacos plásticos. Já os frutos de mamona foram postos ao sol para eclodirem e as sementes, armazenadas em sacos plásticos no LTPF, até o encaminhamento para as extrações de óleos.

Decorrido o período da secagem, foram retiradas quatro amostras representativas dos lotes de sementes das espécies em estudo. Com estas sementes, foram determinados o teor de umidade e o rendimento em óleos de cada oleaginosa em estudo.

\subsection{Determinação do teor de umidade das sementes}

Para a determinação do teor de umidade das sementes, empregou-se o método de destilação, descrito pela Technical Association of the Pulp and Paper Industry - TAPPI T 208 om-94 (TAPPI, 1994), ao empregar o tolueno. Para que o tolueno possa ser utilizado, deve ser saturado com água destilada, a fim de que não se hidrate com a umidade extraída do material durante o processo de destilação. Para isto, foram adicionados $25 \mathrm{~mL}$ de água destilada para 500 $\mathrm{mL}$ de tolueno. A mistura foi transferida para um balão volumétrico de $1.000 \mathrm{~mL}$ e submetida à agitação durante cinco minutos. Após agitada, a mistura ficou em repouso por 15 minutos e o tolueno foi separado da água, ao empregar um funil de decantação, e transferido para um balão de fundo chato de 1.000 $\mathrm{mL}$, sendo mantido sob refluxo durante uma hora.

Pesaram-se $25 \mathrm{~g}$ de sementes em balança de 0,01 $\mathrm{g}$ de precisão. As amostras foram colocadas em um balão de $500 \mathrm{~mL}$, adicionaram-se cerca de $250 \mathrm{~mL}$ de tolueno e foram mantidas sob refluxo durante duas horas, ao empregar um condensador do tipo Liebig e um frasco calibrado do tipo Dean \& Starch, conforme metodologia descrita por Vital (1997). O volume de água foi medido e, como a densidade da água é $1,0 \mathrm{~g} . \mathrm{cm}^{-3}$, o volume foi transformado diretamente em massa. Todas as avaliações foram realizadas em duplicatas. O teor de umidade foi calculado pela Equação 1.

$T U=\left(\frac{M_{A C}}{M_{U}-M_{A C}}\right) * 100$

Em que:

$\mathrm{M}_{\mathrm{AC}}=$ Massa de água coletada no final da destilação (g);

$\mathrm{M}_{\mathrm{U}}=$ Massa úmida da semente $(\mathrm{g})$;

$\mathrm{TU}=$ Teor de umidade da semente em base seca (\%).

\subsection{Determinação do rendimento em óleos nas sementes}

Para a determinação do rendimento em óleos nas sementes das oleaginosas estudadas, foram utilizadas amostras de aproximadamente $70 \mathrm{~g}$. As amostras foram trituradas manualmente, postas em cartucho confeccionado em filtro de papel para café, pesadas e transferidas para um extrator tipo Soxleht acoplado a um balão de $500 \mathrm{~mL}$, contendo $300 \mathrm{~mL}$ de álcool etílico absoluto e mantido sob refluxo durante 5 horas.

Depois da extração, o material restante foi seco em estufa, sendo mantido a $103 \pm 2{ }^{\circ} \mathrm{C}$, durante 24 horas. $\mathrm{O}$ material foi novamente pesado, tendo sido descontada a massa do cartucho. Assim, o rendimento (\%) em óleos, depois de descontada a umidade das sementes, foi obtido pelo emprego da Equação 2. Todas as análises foram em duplicatas.

$T O=\left(\frac{M_{I}-M_{F}}{M_{I}}\right) * 100$

Em que:

$\mathrm{M}_{\mathrm{I}}=$ Massa inicial das sementes $(\mathrm{g})$;

$\mathrm{M}_{\mathrm{F}}=$ Massa após a extração $(\mathrm{g})$;

$\mathrm{TO}=$ Teor de óleos nas sementes (\%).

\subsection{Preparo das soluções com os óleos de nim e mamona}

Estava prevista a extração por cozimento das sementes em água; porém, como o óleo de nim poderia sofrer transformações químicas indesejáveis, este 
foi obtido por meio de extração com solvente, ao se empregar álcool etílico absoluto.

Para a extração com álcool, as sementes, depois de moídas em moinho manual, foram misturadas ao álcool e, posteriormente, homogeneizadas, com o uso de liquidificador doméstico. $\mathrm{O}$ material obtido foi posto em um funil de Büchener de $13 \mathrm{~cm}$ de diâmetro por $4 \mathrm{~cm}$ de altura e filtrado com papel de filtro de filtragem rápida, ao se empregar uma bomba de vácuo acoplada a um Erlemmyer de 2000 mL. Depois da filtragem, observaram-se duas camadas, óleo e solvente, que foram separadas naturalmente com o emprego de um funil de decantação de $500 \mathrm{~mL}$.

O óleo de mamona, após extração e filtragem, ficou miscível no álcool, tendo sido separado por aquecimento e condensação do solvente, ao se empregarem um balão de $1.000 \mathrm{~mL}$, manta aquecedora e um condensador tipo Liebig de $40 \mathrm{~cm}$ de comprimento, e a fração alcoólica foi recuperada e reutilizada.

Depois de tais procedimentos, os óleos foram postos em bandejas de alumínio, cobertas com tecido tipo filó e dispostas no laboratório para a evaporação das porções remanescentes de álcool. Foram preparadas cinco soluções com os óleos obtidos do nim e da mamona. No preparo, foram variadas as quantidades de óleo de nim e de mamona (Tabela 1).

\subsection{Determinação da densidade e da viscosidade das soluções}

Para a determinação da densidade, foram utilizados picnômetros de $250 \mathrm{~mL}$, devidamente secos e tarados, conforme metodologia descrita em Paes (1997), ao dividir a massa de óleo pelo seu respectivo volume à temperatura de laboratório $\left( \pm 25^{\circ} \mathrm{C}\right)$.

Tabela 1. Soluções preparadas com os óleos de nim (Azadirachta indica) e mamona (Ricinus communis).

Table 1. Solutions prepared with neem (Azadirachtaindica) and castor (Ricinus communis) oils.

\begin{tabular}{cl} 
Tratamentos & \multicolumn{1}{c|}{ Soluções de óleos } \\
\hline 1 & Óleo de nim puro \\
\hline 2 & $25 \%$ de mamona e $75 \%$ de nim \\
3 & $50 \%$ de mamona e $50 \%$ de nim \\
4 & $75 \%$ de mamona e $25 \%$ de nim \\
\hline 5 & Óleo de mamona puro \\
\hline
\end{tabular}

A viscosidade foi determinada a $25^{\circ} \mathrm{C}$, com o emprego de viscosímetro tipo Brookfield, no Laboratório de Engenharia Química, na UFCG, em Campina Grande, Paraíba. Todas as determinações foram em duplicatas.

\section{RESULTADOS E DISCUSSÃO}

\subsection{Teor de umidade e rendimento em óleos nas sementes}

Os teores de umidade e o rendimento em óleos das sementes de nim (Azadirachta indica A. Juss) e de mamona (Ricinus communis $\mathrm{L}$ ) encontram-se na Tabela 2. Observa-se que os teores de umidade das sementes variaram em função das características e do processamento de cada semente. O menor teor de umidade das sementes de nim, em relação ao da mamona, provavelmente tenha sido pelo fato de as sementes de nim terem seus tegumentos removidos antes da secagem e as de mamona terem sido secas íntegras.

O rendimento em óleos para as sementes de nim foi superior ao da mamona. O rendimento em óleos obtidos das sementes de mamona está em acordo com os resultados encontrados por Machado et al. (1998), que citaram valores da ordem de 44 a 55\%, e próximo ao citado por Drummond et al. (2006), que obtiveram rendimento de $51 \%$, a utilizar o metanol como solvente para dez variedades de mamona da Região do Agreste do Estado de Pernambuco.

Com relação ao rendimento de óleo das sementes de nim, a Empresa Brasileira de Pesquisa Agropecuária - EMBRAPA (2004) citou o valor de 42\%, porém não faz referência ao método de extração utilizado. Moraes et al. (2008) encontraram rendimento de 47\%, obtido por prensagem das sementes. Considerando-se

Tabela 2. Teor de umidade e rendimento em óleos das sementes de nim (Azadirachta indica) e mamona (Ricinus communis).

Table 2. Moisture content and oils yield of neem (Azadirachta indica) and castor (Ricinus communis) seeds.

\begin{tabular}{ccc} 
Sementes & $\begin{array}{c}\text { Teor de Umi- } \\
\text { dade (\%) }\end{array}$ & $\begin{array}{c}\text { Rendimento em } \\
\text { Óleos (\%) }\end{array}$ \\
\hline Nim & 5,04 & 53,55 \\
Mamona & 5,93 & 49,35 \\
\hline
\end{tabular}


Tabela 3. Densidade e viscosidade das soluções preparadas com os óleos de nim (Azadirachta indica) e mamona (Ricinus communis).

Table 3. Density and viscosity of solutions prepared with neem(Azadirachta indica) and castor (Ricinus communis) oils.

\begin{tabular}{clcc} 
Tratamentos & \multicolumn{1}{c}{ Soluções de óleos } & Densidade $\left(\mathbf{g} \cdot \mathbf{c m}^{-\mathbf{3}}\right)$ & Viscosidade $(\mathbf{m P a . s})$ \\
\hline 1 & Óleo de nim puro & 0,88 & 124 \\
\hline 2 & 25\% de mamona e 75\% de nim & 0,89 & 201 \\
\hline 3 & $50 \%$ de mamona e 50\% de nim & 0,91 & 325 \\
4 & 75\% de mamona e 25\% de nim & 0,91 & 388 \\
\hline 5 & Óleo de mamona puro & 0,92 & 640 \\
\hline
\end{tabular}

que o método de prensagem não retira a totalidade dos óleos, espera-se que, ao empregar a semente sem o tegumento e com o uso de solventes, o rendimento seja maior.

\subsection{Densidade e viscosidade das soluções}

Os valores de densidade e viscosidade das soluções encontram-se na Tabela 3. A densidade do óleo de mamona foi superior à do óleo de nim, o que afetou os valores das densidades das soluções preparadas com os dois óleos em estudo.

A densidade do óleo de mamona foi próxima à encontrada por Suarez (2006), que foi de $0,914 \mathrm{~g} . \mathrm{cm}^{-3}$. Quanto ao óleo de nim, Machado et al. (2006) obtiveram $0,92 \mathrm{~g} . \mathrm{cm}^{-3}$, um valor, portanto, maior que os obtidos nesta pesquisa. Pode ser que o método de obtenção da densidade empregado por aqueles autores forneça maiores valores, quando comparado ao método do picnômetro empregado por Suarez (2006) e nesta pesquisa.

Com relação aos valores de viscosidade, o óleo de nim foi menos viscoso que o de mamona. Houve um acréscimo na viscosidade à proporção que se aumentou a porcentagem de óleo de mamona na solução. $\mathrm{O}$ valor de viscosidade encontrada para o óleo de nim foi superior ao obtido por Machado et al. (2006), que foi de 73,5 mPa.s. No entanto, o valor da viscosidade do óleo de mamona obtido nesta pesquisa foi inferior ao valor encontrado por Costa et al. (2006), que foi de $992 \mathrm{mPa}$.s. Porém, nenhum dos autores citados faz referência à temperatura em que a viscosidade foi determinada.

A viscosidade está relacionada com a penetração de líquidos na madeira, pois quanto maior a viscosidade, maior a dificuldade de penetração da substância nesse material (Paes, 1997). Assim, esperase que o aumento da proporção de óleo de nim facilite a penetração da solução na madeira.

Espera-se que o óleo de mamona, por aderir bem a superfícies sujeitas ao esfriamento e à ação da água (Machado et al., 1998), melhore a fixação dos princípios ativos do óleo de nim na parede celular, prolongando sua eficiência no tratamento da madeira.

\section{CONCLUSÕES}

As sementes de nim tiveram maior rendimento em óleos quando comparadas às de mamona. $\mathrm{O}$ rendimento em óleos de nim obtidos foi superior aos citados na literatura. O rendimento em óleos das sementes de mamona está condizente com os valores encontrados na literatura.

A densidade do óleo de nim foi inferior ao da mamona. O valor de densidade do óleo de nim foi inferior aos obtidos na literatura, enquanto a densidade do óleo de mamona foi próxima aos valores obtidos.

O óleo de nim foi menos viscoso que o da mamona e, à proporção que se incrementou a quantidade de óleo de nim na solução, diminuiu-se sua viscosidade.

\section{AGRADECIMENTOS}

Ao Conselho Nacional de Desenvolvimento Científico e Tecnológico - CNPq, pela Bolsa de Produtividade em Pesquisa (309461/2006-5) concedida ao primeiro Autor, e pela Bolsa de Iniciação Científica, ao segundo Autor. 


\section{STATUS DA SUMISSÃO}

Recebido: 23 Jun., 2013

Aceito: 10 Out., 2014

\section{AUTOR(ES) PARA CORRESPONDÊNCIA}

\section{Juarez Benigno Paes}

Departamento de Ciências Florestais e da

Madeira, Universidade Federal do Espírito Santo

- UFES, Avenida Governador Lindemberg, 316,

Centro, CEP 29550-000, Jerônimo Monteiro, ES,

Brasil

e-mail: jbp2@uol.com.br

\section{REFERÊNCIAS}

Araújo LVC, Rodriguez LCE, Paes JB. Características físico-químicas e energéticas da madeira de nim indiano. Scientia Forestalis 2000; (57): 153-159.

Carvalho GA, Santos NM, Pedroso EC, Torres AF. Eficiência do óleo de nim (Azadirachta indica A. Juss) no controle de Brevicoryne brassicae (Linnaeus, 1758) e Myzus persicae (Sulzer, 1776) (Hemiptera: Aphididae) em couve-manteiga Brassica oleracea Linnaeus var. acephala. Arquivos do Instituto Biológico 2008; 75(2): 181-186.

Companhia Energética de Minas Gerais - CEMIG. Programa estadual de energia de biomassa: subprograma de óleos vegetais carburantes. Belo Horizonte: CEMIG; 1986.

Costa TL, Duarte MEM, Beltrão NE, Paixão FJR, Ribeiro D. Estudo da viscosidade do óleo de mamona para temperaturas na faixa de 20 a $80{ }^{\circ} \mathrm{C}$. Biodieselbr. com [online] 2006 [cited 2008 Jul. 30]. Available from: http://oleo.ufla.br/anais_02/artigos/t085.pdf.

Drummond ARF, Gazineu MHP, Almeida L, Souto Maior A. Metanol e etanol como solventes na extração de óleo de mamona. In: Anais do I Congresso da Rede Brasileira de Tecnologia do Biodiesel [CD ROM]; 2006; Brasília. Brasília: Ministério da Ciência e Tecnologia:Associação Brasileira das Instituições de Pesquisa Tecnológica; 2006.

Empresa Brasileira de Pesquisa Agropecuária - EMBRAPA. Nim indiano [online]. Colombo: EMBRAPA; 2004 [cited 2008 Jul. 30]. Available from: http://www.cnpf.embrapa.br/publica/folders/ Nim_2004.pdf.

Machado CC, Garcia AR, Silva E, Souza AP. Análise técnico-econômica do uso dos óleos de mamona (Ricinus communis, L.) e mineral como lubrificantes do conjunto de corte de motosseras. Revista Árvore 1998; 22(1): 123-134.
Machado GO, Calil C Jr, Polito W, Pawlicka A. Preservante natural de madeira para uso na construção civil: óleo de neem. Revista Minerva: Pesquisa e Tecnologia [online] 2006 [cited 2008 maio 01]; 3(1): 1-8. Available from: http://www.fipai.org.br/Minerva $\% 20$ 03(01)\%2001.pdf.

Martinez SS. O Nim-Azadirachta indica: natureza, usos múltiplos, produção. Londrina: Instituto Agronômico do Paraná; 2002. 142 p.

Moraes ARA, May A, Lourenção AL, Pinheiro MQ. Nim (Azadirachta indica A. Juss) [online]. 2008 [cited 2008 Jul. 30]. Available from: http://www.iac.sp.gov.br/ Tecnologias/Nim/nim.htm.

Mossini SAG, Kemmelmeier C. A árvore nim (Azadirachta indica A. Juss): múltiplos usos. Acta Farmacêutica Bonaerense 2005; 24(1): 139-148.

Paes JB, Souza AD, Lima CR, Medeiros PN No. Eficiência dos óleos de nim (Azadirachta indica) e de mamona (Ricinus communis) na proteção da madeira de sumaúma (Ceiba pentandra) contra cupins xilófagos em ensaio de preferência alimentar. Revista Árvore 2011; 35(3): 751-758

Paes JB, Souza AD, Lima CR, Medeiros Neto PN. Eficiência dos óleos de nim e mamona contra cupins xilófagos em ensaio de alimentação forçada. Cerne 2010; 16(1): 105-113.

Paes JB, Souza AD, Lima CR, Souza PF. Eficiência dos óleos de nim (Azadirachta indica A. Juss.) e mamona (Ricinus communis L.) na resistência da madeira de sumaúma (Ceiba pentandra(L.) Gaerth.) a fungos xilófagos em simuladores de campo. Ciência Florestal 2012; 22(3): 617-624.

Paes JB. Efeitos da purificação e do enriquecimento do creosoto vegetal em suas propriedades preservativas [tese]. Viçosa: Universidade Federal de Viçosa; 1997. 143 p.

Soglia MC, Osório ACB, Santos Neto C, Fancelli M, Macêdo EF, Nascimento AS. Usos e aplicações do nim (Azadirachta indica) [online]. 2006 [cited 2013 Jun. 23]. Available from: http://www.preservamundi.com.br/ portal/index.php/canal-preserva/duvidas/87-duvidastire-aqui/artigos-sobre-neem/108-usos-e-aplicacoesdo-nim-azadirachta-indica.html.

Suarez P. O óleo de mamona como matéria-prima para o biodiesel. Biodieselbr.com [online] 2006 [cited 2008 Jul. 30]. Available from: http://www.biodieselbr. com/colunistas/suarez/oleo-mamona-materia-primabiodiesel.htm.

Technical Association of the Pulp and Paper Industry - TAPPI. TAPPI - T208 om-94: moisture in wood, pulp, paper, and paperboard by toluene distillation. Atlanta: Tappi Press; 1994.

Ventura C. Mamona: lançada variedade mais produtiva. Revista Balde Branco 1990; 26(304): 22-25.

Vital BR. Métodos para determinação do teor de umidade da madeira. Viçosa: SIF; 1997. Boletim Técnico SIF, 13. 